\title{
Comparison of Fatigue Criteria for Combined Bending-Torsion Loading of Nitrided and Virgin Specimens
}

\author{
Š. Major, ${ }^{1, a}$ J. Papuga, ${ }^{2, b}$ J. Horníková, ${ }^{1, c}$ and J. Pokludad ${ }^{1, d}$ \\ ${ }^{1}$ Brno University of Technology, Brno, Czech Republic \\ ${ }^{2}$ Czech Technical University, Prague, Czech Republic \\ a ymajor02@stud.fme.vutbr.cz, ${ }^{\mathrm{b}}$ papuga@pragtic.com, ${ }^{\mathrm{c}}$ hornikova@fme.vutbr.cz, \\ d pokluda@fme.vutbr.cz
}

This work deals with fatigue lffe of plasma-nitrided and virgin specimens made of a low-alloy high strength steel. Specimens were subjected to an in-phase combined bending-torsion loading. The plasma-nitrided specimens exhibited a significantly improved fatigue resistance. The criterion proposed by McDiarmid was found to be the most precise in the fatigue life prediction for virgin specimens. On the other hand, the Matake criterion was the most successful for nitrided specimens.

Keywords: fatigue life, bending-torsion, nitrided layer, high-strength steel.

Motivation of the Research. Many new stress-based multiaxial criteria have been proposed in recent years [1-4]. However, there is still significant lack of their experimental verification. In order to partially fill this gap, in-phase combined bending-torsion experiments were performed using specimens made of a low-alloy high-strength steel (virgin specimens). Similar experiments were carried out on specimens containing surface nitrided layers (nitrided specimens). An extended comparison between classical and advanced multiaxial criteria as well as fatigue life of virgin and nitrided specimens was performed.

Multiaxial Criteria. More than ten classical and advanced multiaxial criteria were utilized to predict the fatigue life under combined bending-torsion. The complete set of criteria can be found elsewhere [2]. Hereafter, only some of them will be mentioned in more detail.

The most general form of fatigue criteria can be given as the inequality

$$
a f(C)+b g(N) \leq f_{-1},
$$

where $a$ and $b$ parameters are set from two uniaxial fatigue limits (e.g., the fatigue limit in the fully reversed torsion $t_{-1}$ and in the fully reversed push-pull $f_{-1}$ ). The linear combination of shear $(C)$ and normal $(N)$ stresses in Eq. (1) can be also replaced by a quadratic version. If the load data on the left-hand side (LHS) of Eq. (1) correspond to an experimentally determined fatigue limit, the ideal state of equality should be achieved. The fatigue index error $I$ represents the degree of deviation from the ideal equality,

$$
I=[(\text { LHS }- \text { RHS }) / \text { RHS }] \cdot 100 \% \text {. }
$$

The ideal prediction leads to LHS $=$ RHS, i.e., $I=0$. If $I>0$, the criterion yields conservative results since it predicts the failure of the specimen (component) under lower loads.

Criteria proposed by McDiarmid, Matake, and Spagnoli can be considered as classical ones. The McDiarmid criterion can be written as

$$
\frac{C_{a}}{t_{A, B}}+\frac{N_{\max }}{2 S_{u}} \leq 1,
$$


where $S_{u}$ is the ultimate strength. The subscript a means the amplitude and the subscript max denotes the maximum stress value. The shear fatigue strength $t_{A, B}$ for case $A$ or case $B$ cracking (parallel to the surface or inwards from the surface, respectively). The relation $t_{A, B}=t_{-1}$ is generally fulfilled for plane bending combined with torsion [5-6].

The Matake criterion can be expressed by the relation

$$
\kappa C_{a, M S S R}+(2-\kappa) N_{\max , M S S R} \leq f_{-1} .
$$

In this equation the fatigue limit ratio $\kappa=f_{-1} / t_{-1}$. The subscript MSSR means the critical plane set according to the Maximum Shear Stress Range criterion.

As an example of the quadratic form, the Spagnoli criterion [7] can be mentioned,

$$
\sqrt{\kappa^{2} C_{a}^{2}+N_{\max }^{2}} \leq f_{-1}
$$

The criteria put forward by Papadopoulos (integral approach) [8] and Goncalves et al. [9] are examples of advanced approaches. In the Papadopoulos criterion the input variables (the shear stress and the normal stress) are integrated over all planes,

$$
\sqrt{\frac{5 \kappa^{2}}{8 \pi^{2}} \int_{\varphi=0}^{2 \pi} \int_{\psi=0}^{\pi} \int_{\chi=0}^{2 \pi}\left(T_{a}(\varphi, \psi, \chi)\right)^{2} d \chi \sin \psi d \psi d \varphi}+(3-3 \kappa) \sigma_{H, \max } \leq f_{-1}
$$

where $T_{a}$ is the amplitude of resolved stress, $\varphi, \psi$, and $\chi$ are the Euler angles, and $\sigma_{H, \max }$ is a maximum value of the hydrostatic stress.

The Goncalves criterion is expressed as

$$
\frac{\kappa-1}{\sqrt{2}(1-1 / \sqrt{3})} \sqrt{\sum_{i=1}^{5} d_{i}}+\frac{\sqrt{3}-\kappa}{\sqrt{3}-1} \sigma_{1, \max } \leq f_{-1},
$$

where the parameters $d_{i}$ can be determined from minimum and maximum values of the transformed deviatoric stress tensor

$$
d_{i}=0.5\left(\max s_{i}(t)-\min s_{i}(t)\right) .
$$

Experimental Procedure. The specimens were made of the high-strength low-alloy steel CSN 415340 . The basic mechanical properties of the material are $\sigma_{y}=805 \mathrm{MPa}$ and $S_{u}=930 \mathrm{MPa}$. One of the surface treatment methods improving the fatigue life is the deposition of nitriding layers by a plasma discharge [10]. The nitriding process parameters are shown in Table 1. The experiments were made by means of the multiaxial-test machine MZGS-100 at room temperature. The applied loading of frequency $29 \mathrm{~Hz}$ comprised symmetric $(R=-1)$ sinusoidal bending and torsion and their in-phase combination.

$\mathrm{T}$ a $\mathrm{b} 1 \mathrm{e} 1$

Nitriding Process Parameters

\begin{tabular}{|c|c|c|c|c|c|c|c|}
\hline Step & $\begin{array}{c}\text { Temperature } \\
\left({ }^{\circ} \mathrm{C}\right)\end{array}$ & $\begin{array}{c}\text { Wall } \\
\left({ }^{\circ} \mathrm{C}\right)\end{array}$ & $\mathrm{N}_{2} / \mathrm{H}_{2}$ & $\begin{array}{c}\text { Compression } \\
(\mathrm{Pa})\end{array}$ & $U, \mathrm{~V}$ & $\begin{array}{c}\text { Pulse } \\
(\mu \mathrm{s})\end{array}$ & $\begin{array}{c}\text { Time } \\
(\mathrm{h})\end{array}$ \\
\hline Refining & 510 & 460 & $20 / 2$ & 70 & 800 & 100 & - \\
\hline Nitriding & 515 & 455 & $21 / 7$ & 260 & 530 & 120 & 32 \\
\hline
\end{tabular}


Comparison of Fatigue Criteria..

$\mathrm{T}$ a b l e 2

The Average $I_{a v}$ and Absolute Average $I_{a b s, a v}$ Values of Error Indices

\begin{tabular}{|l|c|c|c|c|c|}
\hline \multirow{2}{*}{ Criterion } & Specimens & \multicolumn{2}{c|}{ virgin } & \multicolumn{2}{c|}{ nitrided } \\
\cline { 2 - 6 } & Indices (\%) & $I_{a b s, a v}$ & $I_{a v}$ & $I_{a b s, a v}$ & $I_{a v}$ \\
\hline Dang Van & 7.35 & -3.03 & 8.45 & -0.35 \\
\hline Crossland & 7.28 & -5.42 & 8.65 & -2.47 \\
\hline Sines & 11.85 & -11.23 & 12.32 & 12.82 \\
\hline McDiarmid, Eq. (3) & 7.08 & -3.02 & 8.65 & 1.72 \\
\hline Findley & 7.08 & -3.38 & 8.62 & -0.87 \\
\hline Matake, Eq. (4) & 7.12 & -3.04 & 8.32 & -0.23 \\
\hline Spagnoli, Eq. (5) & 10.50 & 4.33 & 8.56 & 3.35 \\
\hline Papadopoulos (integral approach), Eq. (6) & 7.36 & -3.04 & 8.46 & -0.35 \\
\hline Papadopoulos (critical plane) & 11.08 & -6.30 & 16.56 & -6.70 \\
\hline Goncalves et al., Eq. (7) & 8.62 & 4.14 & 13.92 & 5.20 \\
\hline
\end{tabular}

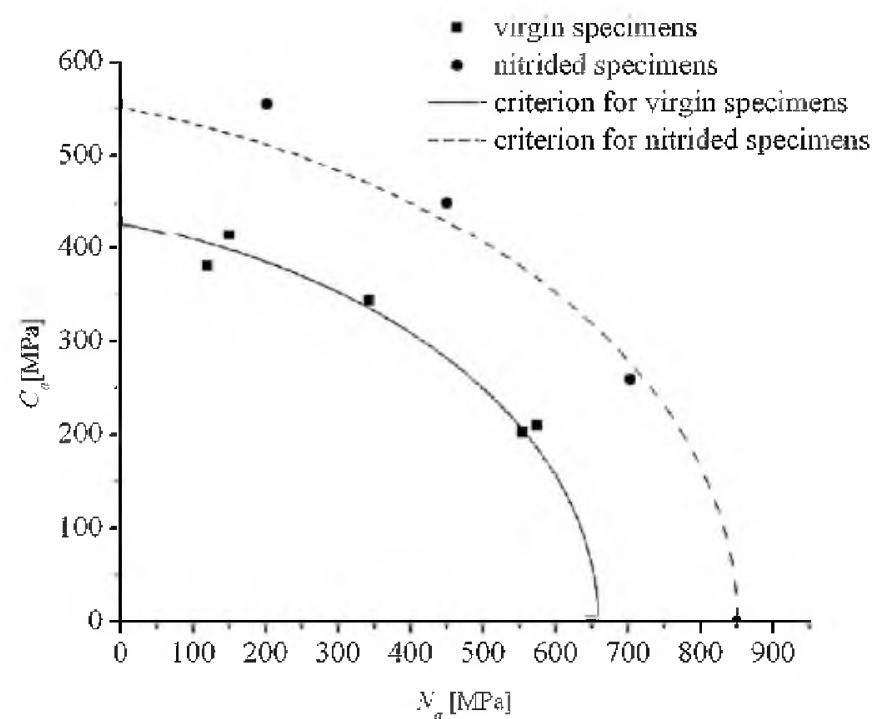

Fig. 1. The constant life diagram ( $n=5 \cdot 10^{5}$ cycles) according to the McDiarmid criterion for virgin and plasma-nitrided specimen.

Conclusions. Our results show that the fatigue life of the nitrided specimens is significantly higher than that of the virgin specimens. The curves are plotted using the McDiarmid criterion for the number of cycles $n=5 \cdot 10^{5}$ and the experimental data correspond to the fatigue life of $(5 \pm 2) \cdot 10^{5}$. This conclusion can be made even though a relatively small number of investigated nitrided specimens were tested. The calculated error indices reveal that the McDiarmid criterion was the most successful in the fatigue life prediction for virgin specimen and the Matake criterion was the most successful for nitrided ones.

Acknowledgments. This research was supported by the Czech Science Foundation under the Project No. GA106/05/0550 and the Ministry of Education and Youth of the Czech Republic under the Research Plan MSM 0021630518. 
1. D. F. Socie and G. B. Marquis, Multiaxial Fatigue, Warrendale (2000).

2. J. Papuga, Mapping of Fatigue Damages, PhD Thesis, Czech Technical University in Prague, Prague (2005).

3. I. V. Papadopoulos, P. Davoli, P. Gorla, et al., Int. J. Fatigue, 19, No. 3, 219-235 (1997).

4. I. V. Papadopoulos, Int. J. Fatigue, 16, 377-384 (1994).

5. D. L. McDiarmid, Fatigue Fract. Eng. Mater. Struct., 14, No. 4, 429-453 (1991).

6. D. L. McDiarmid, Fatigue Fract. Eng. Mater. Struct., 17, No. 12, 1475-1484 (1994).

7. A. Carpinteri and A. Spagnoli, Int. J. Fatigue, 23, 135-145 (2001).

8. I. V. Papadopoulos, Fatigue Fract. Eng. Mater. Struct, 21, 269-285 (1998).

9. C. A. Gonçalves, J. A. Araujo, and E. N. Mamiya, Int. J. Fatigue, 27, 177-187 (2005).

10. J. Pokluda, I. Dvỡák, Ŝ. Major, and H. Horáková, in: W. S. Johnson (Ed.), Fatigue 06, Elsevier (2006).

Received 28. 06. 2007 